\title{
Effect of the Implementation of the Family Physician Program 2015 on Fair Accessibility for People to Health Care Services in the Sistan Region
}

\author{
Mohammad Sarani ${ }^{1}$, Azizollah Arbabisarjou ${ }^{2}$, Soleyman Saravani ${ }^{3}$, Ali Miri $^{1} \&$ Aziz Shahrakivahed ${ }^{4}$ \\ ${ }^{1}$ School of Health, Zabol University of Medical Sciences, Zabol, Iran \\ ${ }^{2}$ Health Promotion Research Center, Zahedan University of Medical Sciences, Zahedan, Iran \\ ${ }^{3}$ School of Medicine, Zabol University of Medical Sciences, Zabol, Iran \\ ${ }^{4}$ School of Nursing and Midwifery, Zabol University of Medical Sciences, Zabol, Iran \\ Correspondence: Soleyman Saravani, School of Medicine, Zabol University of Medical Sciences, Zabol, Iran. Tel: \\ 98-91-5140-2681. E-mail: saravani_solyman@yahoo.com
}

Received: December 13, 2015 Accepted: March 26, $2016 \quad$ Online Published: April 29, 2016

doi:10.5539/gjhs.v8n12p20 URL: http://dx.doi.org/10.5539/gjhs.v8n12p20

\begin{abstract}
Equitable access to primary health care is an indispensable right and a basic need of all human beings. Currently, the development of any society is judged based on the level of public access to primary health care services. This comparative study attempted to examine the fairness accessibility of people in Sistan to health care services through Family Physician Program 2015.

This was a descriptive, analytical research focusing on the level of equitable public access to primary health care in Sistan. Samples were taken from all the service-providing centers. Data were collected through HNIS software, network management center to analyze the gathered data. The results showed that prior to the implementation of the family doctor plan (before 2005), there was a doctor for every 9545 people, a midwife for every 10,000 people and one paramedic for 1,111 people. After beginning the family doctor plan, the figures showed that there was one doctor or MD for every 3387 people and one midwife for every 2916 people, and one health worker for every 549 rural residents. The implementation of the family physician program was an opportunity for the health system in Sistan region, where the appropriate resources management and equitable distribution of health care services throughout the region could facilitate accessibility to identical services.
\end{abstract}

Keywords: equitable access, family physician program, Sistan, health care services

\section{Introduction}

A family doctor holds at least a Doctorate of Medicine (M.D) in medical professions as well as a valid certification. At the primary level of services, a family physician is responsible for the primary level of medical services such as concentrating on the comprehensiveness of the services, continuity of services, health management, research and coordination with other departments (David, 2009).

The Family Physician Program (FPP) is responsible for health services within a defined package (service pack), without discrimination of age, gender, social and economic characteristics and risks of the individual patients, family, community and society under coverage. An FPP, if necessary, should refer the patient to higher levels of service so as to maintain and improve the health of the person, even though he will remain responsible for following up the health practices. The family physician is responsible for managing the health care team (Majidi, 2014).

The family physician is deemed by authorities as a person with generalist capabilities. The expertise is based on three axes of knowledge, attitude and service delivery. Knowledge and attitude needed to fill such position resembles those of other professions as defined by the scope of required skills. However, the care services differ from those of other professional groups, since it serves to evaluate the public assess to services, efforts to establish justice in the enjoyment of health facilities, effort to respond to the needs of society, regardless of the financial, economic, gender, race and other conditions. He has a duty to assess the living conditions of target groups and curtail the health risk factors through top priority (Takian, 2015). 
Equitable access to primary health care is an indispensable right and a basic need of all human beings. Currently, the development of any society is judged based on the level of public access to primary health care services nationwide (Grail, 2011).

In regions where health services are inadequate for the large number of people or the services is poorly distributed, there should be a basic care network or be entirely refurbished in terms of structure. These regions are always facing internal conflict or a variety of events and the wrath of nature. At the same time, they are deprived of services not just the health sector but also other sectors, leading to problems in the provision of health care and the establishment and maintenance of personnel. Planners in those regions find themselves facing with strategic choices, whether to provide several limited services to its entire people, or develop it through a slow expansion as a comprehensive package of primary care in suburban areas (Razavi, 2006).

From the perspective of the World Health Organization (WHO), a family physician is the global effort to improve service quality, reduce costs, and enhance effectiveness and equality in health care systems. 56 countries had established a family physician program until 1997. The UK is one of the pioneers of the family doctor plan, implementing it for about 70 years. This plan in the UK consists of a national system of care of the second and third levels with this feature that first level care has been transferred to the private sector. The percentage of doctors involved in the primary care system is $50 \%$, while there are $26 \%$ of new graduates entering the field. In this system, medical students after high school take part in a 5-year course and then pass a 12-month internship followed by a permission to work or choose a Specialty (Shabir, 2013).

According to article 91 of the Fourth Economic, Social and Cultural Development Plan of Islamic Republic of Iran (2005-2009) was stating that necessary measures should performed to establish the health insurance and execute the FPP and the referral system up to the end of the fourth development plan, the FPP has been executed with the cooperation of the Ministry of Welfare and Social Security and the Ministry of Health and Medical Education in nomadic and rural areas and cities with a population fewer than 20,000 people since late March, 2005 (the begin of the Iranian year) (Khadivi, Golshiri, Farasat, \& Khaledi, 2013; Torabian, Cheraghi, \& Azarhomayoon, 2013). Considering a physician is not selected by people but by the Family Physician Program Management in healthcare center of each city, each physician covers 4,000 people in the program and people cannot choose their own family physician (Khadivi et al., 2013). Family physicians are general practitioners (Ministry of Health and Medical Education [Mohme], 2012) and a few of them have received training for the family physician (Bardella, 2009).

The design of health systems was based on a broad and comprehensive view covering both urban and rural areas. The tasks were assigned to all health service providers at all levels. During implementation, however, some factors hindered health systems mainly in rural areas, while it developed in the cities and in practice, the hospitals failed to follow the expansion of health networks (Shabir, 2013).

Given the history of 70-year family doctor plans in many countries, one of the most effective strategies of increasing access and equitable utilization of health services involves a FDP. This plan not only provides services to the public, but also curtails the possibility of misuse of the public health needs by certain health care providers (Edwin, 2015). In the 1970 in Iran, the policy emphasis was on prevention as a long-term investment, allocation of resources to rural and less-privileged areas and priority in patient treatment over outpatient treatment, a rural network to monitor the approximately 2,500 rural health centers. The employees at those centers were supervised by doctors, midwives, nurses, midwives, nurses and medical technicians. Each health center administered 1 to 5 smaller centers under the name of health houses, which amounted to 17000 units covering 90 percent of the rural population under health care services. In remote villages, the employees at health centers are locally called Behvarz or social worker. Social workers (employees with several health records) are elected by the people, are trained 12 to 18 months are then employed by the government. Urban teams trained based on problem-solving methods and provided supervision and support. The government began to implement this strategy and gradually developed into other provinces. Over many years, the PHC network has grown and today, the place where services are provided is nearer to where the people are working and living. Moreover, assistant staff has been trained to provide primary health care services to millions of rural people. The benefit of services rural areas is now equal to that in urban areas. The gradual development of this system curtailed the distance between the village and city, thus reducing child mortality (Majidi, 2014). "Care with high quality for all" is one of the most priorities for next ten years of health services reform. This care is accessable in location and included asatisfied experience and pleasant (Arbabisarjou, 2012).

Throughout the gradual expansion of primary care network, there are a number of limiting factors such as lack of permanent staff and retention of middle level employees who can organize activities necessary for establishing 
sustainable results among the general population for years onwards (Butler, 2012). When the network expansion is directed only for administrative tasks, it leads to despair, However, when for pressure running the short-term activities are fully controlled, it will be easier to respond to the needs, demand and participation of the main actors and entire society, so as to establish a strong foundation of primary care networks, even where there is a severe shortage of resources and difficulties such as local conflicts and post-conflict conditions (Nasrollahpour, 2010).

People expect a fair distribution of health system services, but the roots of inequalities in social conditions out of control directly affect the health system. This problem can be tackled through government support and cross-sectoral measure (Bailey, 2006). Moreover, the health system can take internal measures to effectively expand health justice. It can be realized based on a series of reforms with the aim of progressing towards universal coverage, i.e. towards access of all people to health services through social protection, securing resources and constant FPP (Janati, 2010).

\section{Methodology}

This was a descriptive, research focusing on the level of equitable public access to primary health care in Sistan before and after the implementation of the FPP. The number of units in structural terms as well as health centers, laboratories, urban and rural centers and manpower, physician, health workers, health workers, midwives, as well as considering the proportion of doctors to population was examined. The accessibility of all of the rural population covered and sparsely populated cities was estimated to be one physician per 4,000 people, on average. The samples were taken from all the unit offering first level of service, including: 212 health houses, 54 rural health centers, 15 e rural and urban health centers and 17 health stations. The data collection tool was based on HNIS (Health Net's, 2010) software network management center and these data was analyzed by the network structure.

Sistan Region: Sistan (Persian/Baloch/Pashto:), known in ancient times as Sakastan (Persian/Baloch/Pashto:; "the land of the Saka"), is a historical and geographical region in present-day eastern Iran (Sistan and Baluchestan Province), southern Afghanistan (Nimruz, Kandahar, and Zabul Province), and the Nok Kundi region of Balochistan (western Pakistan). In the Shahnameh, Sistan is also referred to as Zabulistan, after the region in the eastern part of Iran. In Ferdowsi's epic, Zabulistan is in turn described to be the homeland of the mythological hero Rostam (https://en.wikipedia.org/wiki/Sistan).

\section{Findings}

At the beginning of the FPP in April 2005, the Zabol health center was inaugurated by Minister of Health. For Sistan rural population, there are 22 doctors, one per 9545 people, a midwife for every 10,000 people and one paramedic per 1,111 people. There are 4 laboratory units which as been increased to 15 units after the plan. Furthermore, the dental units were seven increasing to eight after the plan. The number of radiology services at first level was zero while it was 3 units after the plan. According to the population of Sistan and under the standards of expanding health network, there were 53 doctors, 84 midwives, 224 health centers, 54 rural health centers and 15 urban health centers, 17 annexed and non-annexed health centers required. The results showed that before the family doctor plan (before 2005) there has been a physician for every 9545 people, one midwife for every 10,000 people and one paramedic per 1,111 people. In fact, the coverage or the availability of primary health care services, including home health care, urban health centers, rural health centers, and non-annex health centers were $84.3 \%$ before FPP, while after the start of the plan, the statistics revealed a doctor for every 3387 people, one midwife per 2916 people, and a rural health worker for every 549 people. After the implementation of the FPP, the network coverage was $95.1 \%$, which indicated an increase by $10.8 \%$.

Table 1. Comparison before and after the implementation of the FPP in terms of public access to skilled manpower

\begin{tabular}{lllllll}
\hline Variable & $\begin{array}{l}\text { Defined } \\
\text { basis }\end{array}$ & $\begin{array}{l}\text { Before the implementation } \\
\text { of FPP (before 2005) }\end{array}$ & Percentage & $\begin{array}{l}\text { After the implementation } \\
\text { of FPP (after 2005) }\end{array}$ & Percentage & $\begin{array}{l}\text { Percentage } \\
\text { change FPP }\end{array}$ \\
\hline Physician & 70 & 22 & $31 \%$ & 70 & $100 \%$ & 69 \\
Midwife & 59 & 20 & $34 \%$ & 80 & $136 \%$ & 102 \\
Social worker & 421 & 285 & $68 \%$ & 417 & $99 \%$ & 31 \\
Laboratory & 17 & 3 & $18 \%$ & 9 & $53 \%$ & 35 \\
Radiology & 7 & 0 & 0 & 3 & $43 \%$ & 43 \\
Drugstore & 38 & 28 & $74 \%$ & 38 & $100 \%$ & 26 \\
\hline
\end{tabular}


Table 2. Comparison of changing percentages before and after implementation of family doctor plan in terms of public access to health service-providing centers

\begin{tabular}{|c|c|c|c|c|c|c|}
\hline Variable & $\begin{array}{l}\text { Defined } \\
\text { basis }\end{array}$ & $\begin{array}{l}\text { Before the } \\
\text { implementation of } \\
\text { Family Doctor Plan } \\
\text { (before 2005) }\end{array}$ & Percentage & $\begin{array}{l}\text { After the } \\
\text { implementation of } \\
\text { Family Doctor Plan } \\
\text { (after 2005) }\end{array}$ & Percentage & $\begin{array}{l}\text { Percentage of } \\
\text { change after the } \\
\text { family doctor } \\
\text { plan }\end{array}$ \\
\hline $\begin{array}{l}\text { Number } \\
\text { networks }\end{array}$ & 2 & 0 & 0 & 2 & $100 \%$ & $100 \%$ \\
\hline $\begin{array}{l}\text { Number of } \\
\text { health centers }\end{array}$ & 1 & 1 & $100 \%$ & 1 & $100 \%$ & 0 \\
\hline $\begin{array}{l}\text { Number of rural } \\
\text { health centers }\end{array}$ & 40 & 36 & $90 \%$ & 39 & $98 \%$ & $8 \%$ \\
\hline $\begin{array}{l}\text { Number of rural } \\
\text { health centers }\end{array}$ & 16 & 8 & $50 \%$ & 12 & $75 \%$ & $25 \%$ \\
\hline $\begin{array}{lr}\text { Number } & \text { of } \\
\text { annexed } & \text { health } \\
\text { stations } & \end{array}$ & 17 & 8 & $47 \%$ & 12 & $71 \%$ & $24 \%$ \\
\hline $\begin{array}{l}\text { Number of } \\
\text { non-annexed } \\
\text { health stations }\end{array}$ & 7 & 2 & $29 \%$ & 4 & $57 \%$ & $28 \%$ \\
\hline $\begin{array}{l}\text { Number of } \\
\text { health houses }\end{array}$ & 224 & 204 & $91 \%$ & 212 & $95 \%$ & $4 \%$ \\
\hline
\end{tabular}

Table 3. Comparison of access to radiology services, laboratory and dental before and after the implementation of family doctor plan

\begin{tabular}{|c|c|c|c|}
\hline Variable & $\begin{array}{l}\text { Percentage of coverage before } \\
\text { implementation of the family } \\
\text { doctor plan }\end{array}$ & $\begin{array}{l}\text { Percentage of coverage after } \\
\text { implementation of the family } \\
\text { doctor plan }\end{array}$ & $\begin{array}{l}\text { Percentage of change } \\
\text { after the family doctor } \\
\text { plan }\end{array}$ \\
\hline $\begin{array}{l}\text { Radiology } \\
\text { services }\end{array}$ & 0 & $75 \%$ & $75 \%$ \\
\hline Laboratory & $40 \%$ & $90 \%$ & $50 \%$ \\
\hline Oral and dental & $78 \%$ & $88 \%$ & $10 \%$ \\
\hline $\begin{array}{l}\text { Coverage of } \\
\text { health houses }\end{array}$ & $84.3 \%$ & $95.1 \%$ & 10.8 \\
\hline
\end{tabular}

\section{Discussion}

Health constitutes the foundation of family physician activities, generally serving to maintain and improve the health of the community. Nevertheless, patients constitute the foundation of this plan in Iran (Asefzadeh \& rezapour, 2005).

The implementation of FPP was initiated in the villages and cities of less than 20,000 people through issuing health insurance coverage papers. This action was taken in line with health equity, explained in the context of primary health care systems without any structural rearrangement. However, the main reason behind this plan was the ideal structure of the system, which has been continued in the country since 2005 , experiencing several structural and technical changes (Nasrollapour et al., 2008).

The results showed that public access to human resources for services developed from $28.7 \%$ before implementation of FPP to $100 \%$ after the plan. In certain health centers, there was circadian physician involved in providing services to people. Moreover, the midwives before implementation of FPP were involved only in health centers, which were sent to each health care center after implementation of FPP. This indicator before implementation of the FPP was 34\%, while it was promoted to $136 \%$ after implementation of FPP.

In study Barati et al. (2012) titled "the impact of FPP on health indicators in Iran (2003-2007). Statistical analysis showed that the changes in six main indicators during these years including infant mortality rate (IMR), crude birth rate, under-5 mortality rate (U5MR), neonatal mortality rate (NMR), maternal mortality rate (MMR), 
and percentage of deliveries attended by unskilled persons were significant $(\mathrm{P}<0.05)$ and all of the above indicators have decreased during these years. Although other five indicators such as crude death rate (CDR), general fertility rate, percentage of deliveries in hospitals, percentage of family planning coverage and still birth rate had an appropriate improvement during these years,. Their changes were not statistically significant $(\mathrm{P}>0.05)$. Their findings indicated that there has been an acceptable improvement in many of the health indicators since starting this program.

A similar study in 2000 by Janati et al. with subject, Assessing the strengths \& weaknesses of FPP result showed that about $\% 97$ of participants had awareness about FPP implementation; $97.6 \%$ used family physician services and 96.8 have been health insurance. The major strengths of family physician program were: developing the health files for all people, improving prenatal and child care, increasing easy access to physician and medicine, and decreasing health expenditure for people. However, the major weaknesses were: increasing health houses customers, lack of job security and delay in salary payment for family physician team members, and limited availability of physician in health houses.

In study of Khayyati et al. (2011) titled "the role of family physician in Case Finding, Referral, and Insurance Coverage in the Rural Areas, the results showed the presence of physicians in health centers were $75 \%$ and $100 \%$ respectively, for 2004 and 2008 . This rate was $50 \%$ and $100 \%$ for midwives and for the same years respectively. The total referral cases to the hospitals were 2676 , the feedback rate was recorded in $36 \%$ of the cases. In this case the follow up rate by physicians was $0 \%$ in 2004 and $3.17 \%$ in 2008 . Insurance coverage rate was $27 \%$ and $97 \%$ for 2004 and 2008 respectively within a meaningful P- value range at $95 \%$ CI. Too. They findings of this study show that the FPP has the positive impact on function of health units in terms of availability of physicians and midwives.

Human resource as social health workers are the first level of public service which were $68 \%$ before implementation of the family doctor plan and promoted to $99 \%$ after implementation of the family doctor plan. They began to work trough defined services in a network system in all parts of the region. Moreover, the qualified laboratory personnel, radiology and pharmacy operator increased respectively from zero to $18 \%, 74 \%$, $53 \%, 43 \%$ and $100 \%$ after implementation of the family doctor plan.

In a study with subject, The Effect of Implementing Family Physician Program on Health Indices in Kermanshah Province, According to they results, one can argue that the implementation of FPP has had positive impacts on neonatal mortality, infant mortality, under-five mortality and maternal death due to the complications of pregnancy and childbirth, total fertility rate and coverage percentage of FPP (Taha \& Vahdat, 2015).

In terms of public access to services including re equipping and commissioning, the number of networks increased from zero to $100 \%$ after implementation of the FPP, the number of rural health centers from $90 \%$ to $98 \%$, rural and urban centers from $50 \%$ to $75 \%$, annexed health centers from $47 \%$ to $71 \%$, non-Annex health centers from $29 \%$ to $57 \%$ and health houses from $91 \%$ to $95 \%$. Moreover, the availability of laboratory services, including radiology services increased from zero to $75 \%$, laboratory from $40 \%$ to $90 \%$ and the network coverage as one of the indicators examined in this study increased from $84.3 \%$ to $95.1 \%$ after implementation of the FPP. The implementation of FPP provided an opportunity in the Sistan region through establishing health centers across many regions, facilitating access to primary health care services. In fact, the deployment of manpower including doctors, midwives, nurses or social workers and drug technicians provided the rural population with better access to family physician and medical teams. Moreover, by distributing the radiology and laboratory services and strengthening the referral system at the various levels of health care based on the needs of the community across all parts of the region, there was equal access to services by the general public. The services were placed closer to where people live and work, including rural or urban health centers, rural health centers and health houses, where the initial contact with the patients takes place through the family physician or the health care team. The services such as prevention and early treatment, registration of information and referral and follow-up of health records were administered under the family physician services, while the prescription of drugs and laboratory services took place under the same practices.

In a study titled FPP in Iran: Considerations for Adapting, results showed that FPP in Iran can be achieved through fundamental changes in the governance and organization of health system towards greater decentralization; robust transparency, balanced distribution of power among various healthcare providers, adjusted tariff system for medical services, and most importantly educating people to seek their care through referral system (Khayatzadeh-Mahani \& Takian, 2014)

Among the limitations of this study were very few similar studies done in this field, to the extent that there are rare previous study in this regard, making it difficult to compare and match the results with domestic research. 


\section{Conclusions}

This study demonstrated that the FPP increased the public access to primary health care services through a network system. In fact, the index of network coverage increased from $84.3 \%$ before the implementation of the family doctor plan all the way to $95.1 \%$ after the implementation of the family doctor plan through health houses, rural health centers, urban and rural health centers and laboratory services, radiology services as well as the health team. The outcome of such access to services was a reduction in the cost of living, improved quality of life, shortened hospitalization at the second and third levels and ultimately increased life expectancy.

\section{Competing Interests Statement}

The authors declare that there is no conflict of interests regarding the publication of this paper.

\section{References}

Arbabisarjou, A. (2012). Practical Leadership and Management in Nursing. Translated, Tehran: Nashre Jameenegar.

Asefzadeh, S., \& Rezapour, A. (2005). Assessing the Strengths \& Weaknesses of Family doctor plan. Health administration. Hadis Emroz Press, 12(2), 25-35. (In Persian)

Bailey, P., Jones, L., \& Way, D. (2006). Family physician/nurse practitioner: Stories of collaboration. Journal of Advanced Nursing, 16(53), 381-391. http://dx.doi.org/10.1111/j.1365-2648.2006.03734.x

Barati, O., Maleki, M., Gohari, M., Kabir, M. J., Amiresmaili, M., \& Abdi, Z. (2012). The impact of family physician program on health indicators in Iran (2003-2007). Journal of the Iranian Institute for Health Sciences Research (IHSR), 11(3), 361-363.

Bardella, I. J. (2009). International Family Medicine Education. FAM MED, 41(1), 62-64.

Butler, D. C., Petterson, S., Phillips, R. L., \& Bazemore, A. W. (2012). Measures of social deprivation that predict health care access and need within a rational area of primary care service delivery. Health Serv Res. 48(2-Pt-1), 539-559.

David, S. (2009). Introduction to health system reform. Tehran: Contemporary Works, 2009. (In Persian)

Edwin, B. et al. (2015). Contributions of Peer Support to Health, Health Care, and Prevention: Papers from Peers for Progress. Ann Fam Med, 13(Suppl_1), S2-S8.

Grail, M. R., Humphreys, J. S., Joyce, C. M., \& Scott, A. K. (2011). How do rural GPs' workloads and work activities differ with community size compared with metropolitan practice? Aust J Prim Health.

Health Net's software guide structure in Iran. (2010). Retrieved from http://HNIS.behdasht.gov.ir

Janati, A., Maleki, M., Gholizade, M., \& Narimani, M. (2010). Assessing the Strengths \& Weaknesses of Family doctor plan. Journal of Knowledge and Health, 4(4), 39-44. (In Persian)

Khadivi, R., Golshiri, P., Farasat, E., \& Khaledi, G. (2013). Caregiver Satisfaction in Rural Areas in Isfahan district, Iran, after Implementation of the Family Physician Project. J Isfahan Med Sch, 31(244), 1048-1058.

Khayatzadeh-Mahani, A., \& Takian, A. (2014). Family physician program in Iran: Considerations for adapting the policy in urban settings. Arch Iran Med, 17(11), 776-8.

Khayyati, F., Esmaeil, M. M., Kabir, M. J., Kazemeini, H., Gharibi, F., \& Jafari, N. (2011). The Role of Family Physician in Case Finding, Referral, and Insurance Coverage in the Rural Areas. Iranian J Publ Health, 40(3), 136-139

Majidi, A., Loori, N., Shahandeh, K., Jamshidi, E., \& Magdzadeh, R. (2014). Are people in Tehran prepared for the family physician program, 5(8), 984-991. PMC4258677

Nasrollahpour, D., Shirvani, D., Raeisee, P., Motlagh, M. E., Kabir, M. J., \& Ashrafian, A. (2010). Evaluation Of The Performance Of Referral System In Family Doctor Plan In Iran Health System Research Journal Hakim University Of Medical Sciences, 13(1), 19-25. (In Persian)

Razavi, S. M. (2006). Justice in financial participation in the health system: Thinker. Tehran. (In Persian)

Shabir, M., Raymond, D., Bob, M., Steve, R., Stephen, P., \& Akye, E. (2013). Understanding of family medicine in Africa. British Journal of General Practice, 2(2), 63-70.

Shirvani, D. N., Amiri, H. A., Motlagh, M., Kabir, M. J., Maleki, M. R., Monfared, A. S., \& Alizadeh, R. (2008). Evaluation of the Function of Referral System in Family doctor plan in Northern Provinces of Iran. Journal of Babol University of Medical Sciences, 11(6), 46-52. (In Persian) 
Taha, Z., \& Vahdat, S. (2015). The Effect of Implementing Family Physician Program on Health Indices in Kermanshah Province. Int. J. Rev. Life. Sci., 5(5), 1391-1355.

Takian, A., Doshmangir, L., \& Rashidian, A. (2015). The experience of purchaser-provider split in the implementation of family physician and rural health insurance in Iran: An institution, 30(10), 1261-1271.

\section{Copyrights}

Copyright for this article is retained by the author(s), with first publication rights granted to the journal.

This is an open-access article distributed under the terms and conditions of the Creative Commons Attribution license (http://creativecommons.org/licenses/by/3.0/). 